\title{
Evolución de la proteólisis durante la maduración de quesos Danbo elaborados con distintos cultivos iniciadores
}

\author{
Panizzolo, L. A. ${ }^{(1) *}$, Araújo, A. C. ${ }^{(1)}$, Taroco, L. V. ${ }^{(1)}$, Rodríguez, A. ${ }^{(1)}$, Schöpf, G. ${ }^{(2)}$ \\ (1) Cátedra de Ciencia y Tecnología de los Alimentos, Facultad de Química, Universidad de la República, Uruguay \\ (2) Jucar Ltda, Nueva Helvecia, Colonia, Uruguay.
}

Contacto: arodriguez@fq.edu.uy

Recibido: 30/06/2011 - Aprobado: 7/11/2011

\begin{abstract}
Resumen
La determinación de nitrógeno soluble a pH 4,6 (NNC), nitrógeno soluble en ácido tricloroacético (12 \%) (NTCA) y nitrógeno soluble en ácido fosfotúngstico ( 5 \%) (NPTA) se utiliza como índice de maduración de quesos, ya que proporciona información adecuada de la extensión global de la proteólisis. La formación de péptidos y aminoácidos durante la maduración del queso contribuye directamente al desarrollo del sabor y textura del queso, de allí la importancia de conocer si el uso de distintos cultivos iniciadores genera diferencias en el desarrollo de la proteólisis. En este trabajo se estudiaron los cambios proteolíticos durante la maduración de quesos Danbo elaborados con cultivos iniciadores que difieren en la proporción de sus microorganismos componentes: Lote A con: 60 \% Streptococcus thermophilus subsp. thermophilus - 40 \% (Lactococcus lactis subsp. lactis + Lactococcus lactis subsp. cremoris) y Lote B con: 50 \% Streptococcus thermophilus subsp. thermophilus - 50 \% (Lactococcus lactis subsp. lactis y Lactococcus lactis subsp. cremoris). Se analizaron quesos con $0,15,30$ y 45 días de maduración y se determinó contenido de humedad, pH, contenido de nitrógeno en queso y contenido de nitrógeno de las distintas fracciones nitrogenadas. El lote elaborado con un mayor porcentaje de cultivo mesófilo (Lactococcus lactis subsp. lactis y Lactococcus lactis subsp. cremoris), lote B, fue el que presentó mayor proteólisis primaria y mayor formación de oligopéptidos y aminoácidos libres.

Palabras clave: Queso, Danbo, proteólisis, fracciones nitrogenadas.
\end{abstract}

\begin{abstract}
$\underline{\text { Abstract }}$
The determination of soluble nitrogen at pH 4.6 (NNC), nitrogen soluble in trichloroacetic acid (12\%) (NTCA) and nitrogen soluble in phosphotungstic acid ( $5 \%$ ) (NPTA) is used as an index of cheese ripening because it provides tailored information to the global extent of proteolysis. The formation of peptides and amino acids during cheese ripening contributes directly to the development of cheese flavor and texture, hence the importance of knowing whether the use of different starter cultures generate differences in the development of proteolysis. The aim of this paper is to study the proteolytics changes during ripening of Danbo cheeses which were manufactured with starter cultures that differ in the ratio of their microorganisms components: batch A, 60 \% Streptococcus thermophilus subsp. thermophilus - 40 \% (Lactococcus lactis subsp. lactis + Lactococcus lactis subsp. cremoris) and batch B, $50 \%$ Streptococcus thermophilus subsp. thermophilus - 50 \% (Lactococcus lactis subsp. lactis + Lactococcus lactis subsp. cremoris). Cheeses were analyzed at $0,15,30$ and 45 days of ripening by determination of moisture content, $\mathrm{pH}$, nitrogen content in cheese and nitrogen content of nitrogenous fractions. The batch made with a higher ratio of mesophilic cultures (Lactococcus lactis subsp. lactis and Lactococcus lactis subsp. cremoris), batch B, presented the highest primary proteolysis and highest formation of oligopeptides and free amino acids.

Keywords: Cheese, Danbo, proteolysis, nitrogenous fractions.
\end{abstract}

\section{Introducción}

El queso Danbo es un queso de mediana humedad, graso, elaborado por coagulación de la leche por medio de cuajo y/u otras enzimas coagulantes apropiadas. Para su fabricación pueden utilizarse fermentos de bacterias lácticas específicas (Reglamento MERCOSUR, 1996).

En la fabricación de la mayoría de las variedades de quesos se añaden a la leche, previo a la coagulación, cepas de una o más especies de bacterias lácticas cuidadosamente seleccionadas, denominadas cultivos iniciadores o starters, con el objetivo fundamental de iniciar la fermentación. Su función principal es la producción de ácido láctico $\mathrm{y}$, en algunos casos, la producción de compuestos secundarios responsables del sabor y aroma del queso, como ácido acético, acetaldehído y diacetilo. La producción de ácido tiene tres funciones importantes: favorece la actividad del cuajo, ayuda al desuerado de la cuajada, reduciendo así el contenido en humedad del queso, y ayuda a prevenir el crecimiento de bacterias indeseables en el queso (Poveda, 2001). Las enzimas proteolíticas presentes en los fermentos completan la acción del cuajo, liberando péptidos de pequeño tamaño y aminoácidos libres (Desmazeaud y Gripon, 1977); las peptidasas son las responsables de la degradación de los péptidos hidrofóbicos amargos, influyendo positivamente en la calidad 
organoléptica del queso. Los compuestos así formados son, además, el origen de compuestos que intervienen directamente en el sabor de los quesos o constituyen precursores de los compuestos aromáticos (Law et al., 1993; Monnet et al., 1993). En particular los lactococos están dotados de un sistema proteolítico complejo y por ello son los principales agentes proteolíticos en los quesos de pasta prensada tipo Gouda o Saint-Paulin. Debido a esto los lactococos intervienen en la degradación de las caseínas, principalmente por sus proteasas de pared y por sus diferentes peptidasas intracelulares o unidas a la envoltura (Monnet et. al., 1993; Pritchard y Coolbear, 1993).

La maduración es la etapa del proceso de elaboración del queso durante la cual la cuajada fresca se transforma en una masa homogénea y se desarrollan las características organolépticas típicas del queso: aspecto, textura, sabores, aroma. Esto se debe a una serie de cambios bioquímicos, de reacciones glicolíticas, lipolíticas y proteolíticas, estas últimas como las principales causantes de los cambios de textura durante la maduración del queso (Desmazeau y Gripon, 1977; Fox, 1999). La proteólisis en el queso se produce por la acción de las enzimas presentes: las proteinasas de la leche, las enzimas coagulantes, los cultivos iniciadores y otros microorganismos que se desarrollan en el queso (Sánchez-Ponte, 2003). Dentro de la proteólisis se distinguen la proteólisis primaria, que es la responsable de la textura blanda característica al principio de la obtención de la cuajada, y la proteólisis secundaria, en la que se generan péptidos de pequeño tamaño y alta hidrofobicidad que detectados por los receptores del sabor producen la sensación de amargor. Estos péptidos sirven como substratos precursores para las proteinasas y peptidasas bacterianas que los transforman en péptidos más pequeños y aminoácidos libres (Ferrandini Banchero, 2006) como se mencionó anteriormente. Los aminoácidos, provenientes de la degradación de las proteínas durante la maduración del queso, pueden variar en cantidad e incluso en los tipos de aminoácido debido al catabolismo de aminoácidos. Por estas transformaciones pueden encontrarse aminoácidos ausentes en las proteínas de la leche, como es el caso de la ornitina por degradación del acido glutámico (Hemme et al., 1982). En el esquema general del catabolismo microbiano de los aminoácidos en la maduración de los quesos propuesto por Hemme et al. (1982) se encuentra que en una primera etapa los aminoácidos podrían ser degradados por cuatro grupos de enzimas: descarboxilasas, transaminasas, desaminasas y liasas. Estos productos podrían continuar degradándose hasta la formación de compuestos volátiles tales como el amoniaco, cetonas, aldehídos, ácidos, o compuestos azufrados que forman parte del aroma de la mayoría de los quesos (Dumont y Adda, 1978; Curtin y McSweeney, 2004).

Para el estudio químico de la maduración de quesos son utilizados como índices de maduración la determinación de fracciones de nitrógeno soluble (NNC, NTCA y NPTA), que proporcionan información de la extensión global de la proteólisis. El NNC corresponde a los compuestos de nitrógeno solubles a $\mathrm{pH} 4.6$, y se define como nitrógeno no caseínico, ya que las caseínas son insolubles a ese $\mathrm{pH}$, éstos son producidos fundamentalmente por el cuajo y aumentan durante la maduración. Dentro de los NNC también entran las proteínas del suero y las peptonas proteosas, solubles a $\mathrm{pH} 4.6$, aunque su contribución es relativamente menor. Por otro lado, las $\gamma$-caseínas son insolubles a pH 4.6. El ácido tricloroacético (TCA) es un precipitante de proteínas que ha sido ampliamente utilizado como índice de maduración en quesos. Yvon et al. (1989) hallaron que todos los péptidos con menos de siete residuos de aminoácidos eran solubles en TCA al $12 \%$. La renina es responsable de la producción de parte del nitrógeno soluble en TCA $12 \%$, pero las proteinasas y peptidasas del cultivo iniciador también contribuyen considerablemente a la formación del nitrógeno soluble en TCA 12\%. El ácido fosfotúngstico (PTA) es un precipitante de proteínas muy selectivo. El nitrógeno soluble en PTA $(1.0 ; 2.5 ; 5.0 ; 6.0$ y $6.5 \%)$ ha sido ampliamente utilizado como índice de aminoácidos libres en queso, sólo aminoácidos libres y péptidos menores son solubles en PTA 5 \% (Sánchez-Ponte, 2003).

El objetivo de esta investigación fue estudiar, por medio del análisis de las diferentes fracciones nitrogenadas, los cambios proteolíticos durante la maduración de dos quesos Danbo elaborados con diferentes cultivos iniciadores que difieren en la proporción de sus microorganismos componentes.

\section{Materiales y Métodos}

Para el estudio de la proteólisis según el cultivo iniciador se utilizaron quesos Danbo, un lote elaborado con 60 \% Streptococcus thermophilus sub thermophilus - 40\% (Lactococcus lactis subsp. lactis + Lactococcus lactis subsp. cremoris) como cultivo iniciador (lote A) y el otro elaborado con $50 \%$ Streptococcus thermophilus subsp. thermophilus - 50 \% (Lactococcus lactis subsp. lactis + Lactococcus lactis subsp. cremoris) como cultivo iniciador (lote B). De cada lote se analizaron muestras con $0,15,30$ y 45 días de maduración.

Se elaboraron ambos lotes de queso Danbo mediante tecnología tradicional en la planta de Jucar Ltda. Para ello se utilizó una tina de 120 litros, leche tipificada al $3 \%$ de materia grasa, agregado del fermento correspondiente a $35{ }^{\circ} \mathrm{C}$ y maduración por 30 minutos, cuajado con cuajo Genético a $35{ }^{\circ} \mathrm{C}$, corte, desuerado en tina del $20 \%$ y agregado de un $15 \%$ de agua caliente a $70{ }^{\circ} \mathrm{C}$, cocción a $42{ }^{\circ} \mathrm{C}$ por 20 minutos. Pescado en tela y moldeado en moldes de $22 \times 14 \times 14 \mathrm{~cm}$ para hormas de $4 \mathrm{~kg}$ aproximadamente, prensado. Salazón en salmuera a $21^{\circ}$ Baumé por 24 hs. Oreo, y maduración en cámara de maduración a $11^{\circ} \mathrm{C}$

Se tomaron 2 quesos de cada lote para el estudio. La toma de muestra del queso se realiza por calado. El contenido de humedad se determinó por el método de secado convencional en estufa a $105^{\circ} \mathrm{C}$ en cápsulas con arena según la Norma FIL-IDF 4: 1958. La determinación de $\mathrm{pH}$ se realizó con un $\mathrm{pH}$-metro ORION RESERCH digital ionalyzer/501, según Ferrandini Banchero (2006). Para evaluar la proteólisis de los quesos durante el período de maduración, se utilizaron como índices:

- el Nitrógeno soluble a pH 4.4 - 4.6, también llamado Nitrógeno No Caseínico (NNC).

- el Nitrógeno soluble en ácido tricloroacético al $12 \%$, también llamado Nitrógeno No Proteico (NTCA).

- el Nitrógeno soluble en ácido fosfotúngstico $5 \%$ (NPTA).

Los métodos utilizados para el fraccionamiento y la determinación de las fracciones nitrogenadas fueron los descriptos por Ardö y Polychroniadou (1999) y Bütikofer, Rüegg y Ardö (1993). La determinación de Nitrógeno tanto en las muestras de queso como en las distintas fracciones nitrogenadas se realizó por el método de Kjeldahl utilizando la Norma FIL-IDF25:1964. Los resultados se expresaron como \% del Nitrógeno total para cada queso.

Todos los análisis se realizaron por duplicado.

El análisis estadístico de los datos se hizo mediante análisis de varianza (ANOVA) y test de mínima diferencia significativa (LSD) con un $\alpha=0.5$ para comparación de las medias, utilizando el programa estadístico Statgraphics Plus 7.0.

\section{Resultados y Discusión}

Se observó que los valores de $\mathrm{pH}$ entre ambos lotes fueron significativamente diferentes para todos los tiempos de maduración, menos para los 30 días (Figura 1). La mayor diferencia se encontró a los 45 días. El pH del lote B fue mayor al del lote A para los tiempos de maduración 0,15 y 45 días. Dicha diferencia puede atribuirse a la variación en el cultivo iniciador que afecta al $\mathrm{pH}$ final el día de elaboración: el lote A se elaboró con fermento con una diferencia del $10 \%$ adicional en la cantidad de cultivo Termófilo, y los cultivos termófilos poseen poder acidificante de moderado a alto dependiendo de la cepa (Guerrero et al., 1997). 


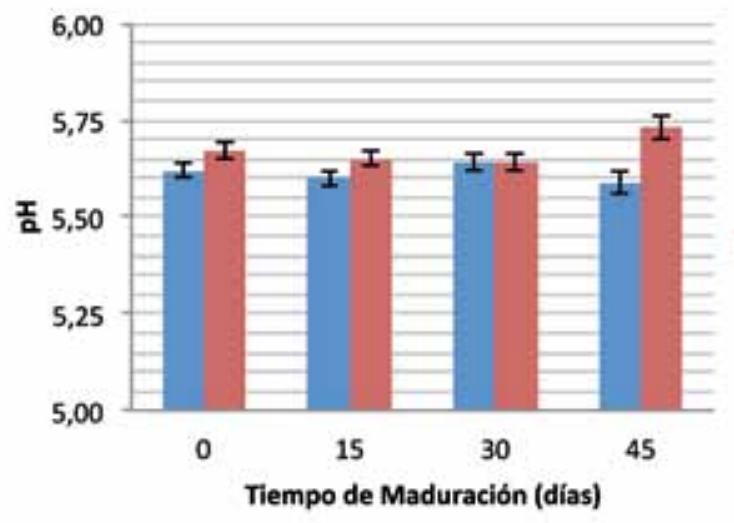

Figura 1. Variación del pH en queso con el tiempo de maduración.

El contenido de humedad disminuyó con el transcurso de la maduración de los quesos tanto en el lote A como en el B (Figura 2). Los valores de contenido de humedad del lote $B$ fueron significativamente mayores a los del lote $\mathrm{A}$ en todos los tiempos de maduración estudiados $(15,30$ y 45 días). Como en el caso del pH, esto podría explicarse por la diferencia en los cultivos iniciadores, ya que cuando ocurre una acidificación más lenta con reducida expulsión de suero se obtienen quesos de mayor humedad (Gómez et al., 1998).

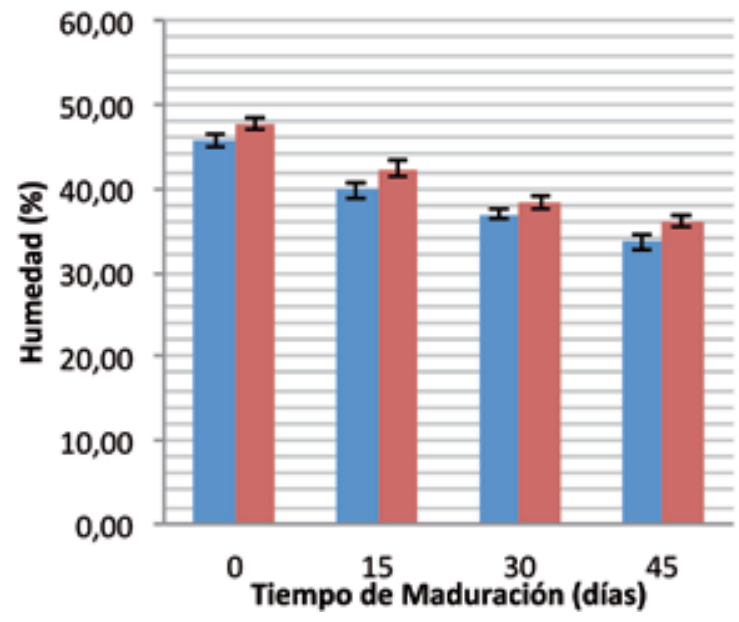

Figura 2. Variación de humedad en queso con el tiempo de maduración.

En el estudio de la proteólisis se observó que la fracción de nitrógeno insoluble a pH 4,6 (NNC) aumentó con el tiempo de maduración para ambos lotes A y B (Figura 3). Esto concuerda con lo observado por Spadoti et al. (2005) en estudios con queso Prato, similar al Danbo, pero que difiere en su elaboración en no ser de masa lavada. Al comparar entre los lotes A y B, se constató que con 0 y 15 días de maduración no existieron diferencias significativas de NNC entre ambos, pero con mayor tiempo de maduración comenzaron a aparecer diferencias significativas: a los 30 días de maduración el NNC del lote A fue mayor al NNC del lote B, mientras que a los 45 días de maduración el NNC del lote $\mathrm{B}$ fue mayor al NNC del lote A.

Poveda (2001) en su estudio de la fracción insoluble a pH 4,6 (NNC) en quesos Manchego elaborados con diferentes cultivos iniciadores (Streptococcus thermophilus y Lactococcus lactis, entre otros), no encontró diferencias entre los lotes para cada tiempo de maduración e indicó que ello podría ser debido a que los agentes responsables de la proteólisis a este nivel (proteólisis primaria) son el cuajo y la plasmina, mientras que las peptidasas del starter actúan sobre los péptidos liberados en la proteólisis primaria, produciéndose así la proteólisis secundaria.

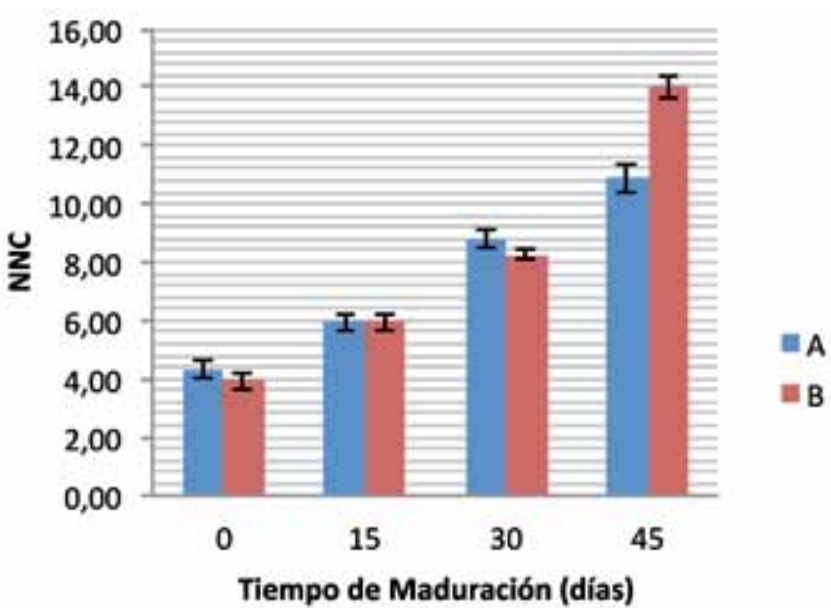

Figura 3. Evolución de la fracción nitrogenada NNC en el queso con el tiempo de maduración.

El hecho de que el NNC del lote B fuese mayor, finalizado el periodo de maduración de 45 días, podría deberse a la riqueza en enzimas proteolíticas de los lactococos, como fue mencionado anteriormente, pero también a la influencia de un mayor contenido de humedad si ambos lotes contuvieran el mismo contenido de sal, como explican Sorensen y Benfeldt (2001). Los valores de NNC obtenidos a los 45 días fueron similares a los obtenidos por Gorostiza et al. (2004) y los expuestos por Spadoti et al. (2005) para el queso Prato.

En cuanto a las fracciones nitrogenadas solubles en TCA 12 $\%$ (NTCA) se puede observar que aumentaron con el tiempo de maduración para ambos lotes (Figura 4). Este aumento de NTCA en el tiempo concuerda con lo informado por otros investigadores, Gorostiza et al. (2004) y Sanchez-Ponte (2003), en estudios en queso Prato y Danbo, respectivamente. Al comparar entre lotes se observó que al inicio la fracción NTCA es significativamente diferente para ambos: el NTCA del lote B fue mayor al NTCA del lote A, pero para los demás tiempos de maduración no se detectó la existencia de diferencias significativas.

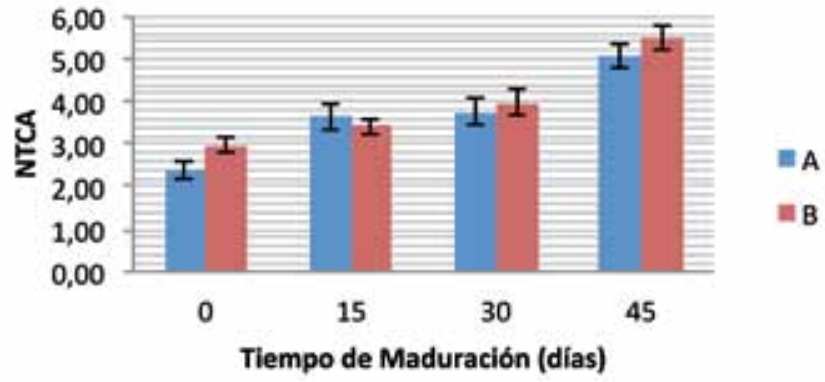

Figura 4. Evolución de la fracción nitrogenada NTCA con el tiempo de maduración.

Los valores de NTCA obtenidos a los 45 días fueron significativamente menores a los obtenidos por Gorostiza et al. (2004) para el queso Prato. Cabe destacar que el queso Prato al no ser de masa lavada no tiene las pérdidas de enzimas como el Danbo (Gorostiza et al., 2004); en conjunto con los diferentes orígenes y calidades de leche, de cuajo, fermentos y variaciones de tecnología, esto podría explicar la diferencia entre los investigadores.

La fracción nitrogenada soluble en ácido fosfotúngstico (NPTA) presentó un aumento continuo durante el tiempo de maduración para ambos lotes (Figura 5). Poveda (2001) informó un aumento de NPTA durante la maduración de Queso manchego elaborado con diferentes cultivos iniciadores y Gorostiza et al. (2004) también consignaron un aumento de aminoácidos totales durante el tiempo de maduración de queso Prato. 


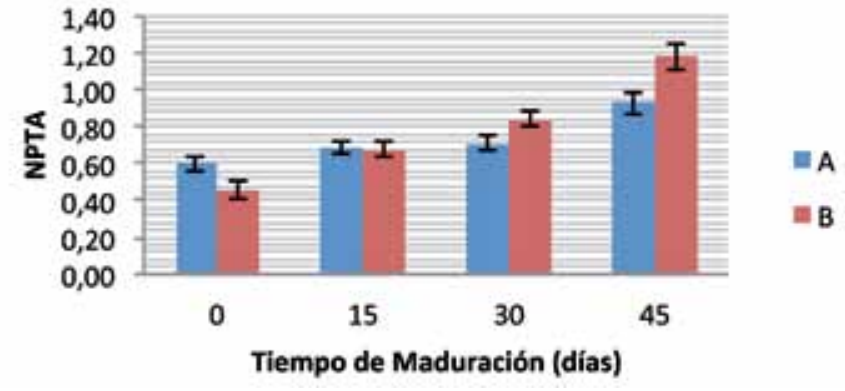

Figura 5. Evolución de la fracción nitrogenada NPTA con el tiempo de maduración.

Al inicio del estudio el NPTA del lote A fue significativamente mayor al del lote $\mathrm{B}$, a los 15 días ya no se presentaron diferencias significativas, mientras que a los 30 y 45 días el NPTA del lote B fue significativamente mayor al NPTA del lote A.

Que el lote B haya presentado un mayor valor de NPTA podría atribuirse a que las proteinasas del lactococos, microorganismo que estaba en mayor proporción en el lote $\mathrm{B}$, presentan un sistema peptidásico capaz de degradar un amplio rango de péptidos de medio y pequeño tamaño a aminoácidos (Lane y Fox, 1996), contribuyendo así a la producción de péptidos pequeños u oligopéptidos $\mathrm{y}$ aminoácidos libres.

\section{Conclusiones}

Se encontraron diferencias en la proteólisis de los lotes de queso Danbo elaborados con diferentes proporciones en los cultivos iniciadores, mediante la determinación de las fracciones de nitrógeno soluble NNC, NTCA y NPTA.

El lote de queso Danbo elaborado con un mayor porcentaje de cultivo mesófilo (Lactococcus lactis subsp. lactis y Lactococcus cremoris subsp. cremoris), lote $\mathrm{B}$, fue el que presentó mayor proteólisis primaria y mayor formación de oligopéptidos y aminoácidos libres.

\section{Referencias}

- ARDÖ, Y.; POLYCHRONIADOU, A. Laboratory manual for chemical analysis of cheese, cost 95: improvement of the quality of the production of raw milk cheeses. Brussels: Office for Official Publications of the European Communities, 1999. pp. 30-42.

- BÜTIKOFER, U.; RÜEGG, M.Y.; ARDÖ, Y. Determination of nitrogen fractions in cheese: evaluation of collaborative study. En: Leberson- Wiss. u. Technol. 1993, 26:271-275.

- CURTIN, A.C.; MC SWEENEY, P.L.H. Catabolism of amino acids in cheese during ripening. En: FOX, P.; MCSWEENEY, P.; COGAN, T.; GUINEE, T. Cheese Chemistry, physiscs and microbiology. 3ra. ed., vol.1. Maryland: Elsevier, 2004. p.435.

- DESMAZEAU, M.J.; GRIPON, J.C. General mechanism of protein breakdown during cheese ripening. En: Milchwissenschaft, 1977, 32: 731-734.

- DUMONT, J. P.; ADDA, J. Occurrence of sesquiterpenes in mountain cheese volatiles. En: Journal of Agricultural and Food Chemistry. 1978, 26(2): 364-367.

- FERRANDINI BANCHERO, E. Elaboración de queso de Murcia al vino con cuajo natural en pasta. Murcia: Universidad de Murcia, 2006. (Tesis de Doctorado)

- FOX, F.P.; LAW, J.; MC SWEENEY, P.L. H; WALLACE, J.. Biochemistry of cheese ripening. En: FOX, F.P. Cheese: chemistry, physics and microbiology. General aspects. 2a. ed., vol.1.
Norwell: Kluwer Academic Publishers, 1999. p. 389.

- GUERRERO, L.; MUSET, G.; PACHECO, L. Evaluación de las actividades enzimáticas de cultivos comerciales usados para la elaboración de quesos. En: Revista Cientifica, FCV-LUZ . 1997, 7(3): 209-214.

- GOMEZ, M. J.; PILAR, G.; NUNEZ, M.; MÉDINA, M. Streptococcus thermophilus as adjunct for a semi-hard cow's milk cheese. En: Lait. 1998, 78(5):501-511.

- GOROSTIZA, A.; CICHOSCKI, A.J.; VALDUGA, A.T.; VALDUGA, E.; BERNARDO, A.; FRESNO, J.M. Changes in soluble nitrogenous compounds, caseins and free amino acids during ripening of artisanal prato cheese; a Brazilian semi-hard cows variety. En: Food Chemistry. 2004, 85:407-414.

- HEMME, D.; BOUILlANE, C.; METRO, E.; DESMAZEAU, M.J. Microbial catabolism of amino acids during cheese ripening. En: Sci. Aliment. 1982, 2:113-123.

- INTERNATIONAL DAIRY FEDERATION (Belgium). IDF 4: Cheese and processed cheese - Determination of the total solids content (Reference Method). Brussels: IDF, 1958

- INTERNATIONAL DAIRY FEDERATION (Belgium). IDF 25: Processed cheese products - Determination of nitrogen content and crude protein calculation - Kjeldahl method. Brussels: IDF, 1964

- LANE, C. N.; FOX, P. F. Contribution of starter and adjunct lactobacilli to proteolysis in Cheddar cheese during ripening. En: International Dairy Journal. 1996, 6:715-728.

- LAW, J.; FITZGERALD, G.F; UNIACKE-LOWE, T.; DALY, C.; FOX, P.F. The contribution of lactococcal starter proteinases to proteolysis in Cheddar cheese. En: Journal Dairy Science, 1993, 76: 2455-2467.

- MERCOSUR. Reglamento técnico MERCOSUR de identidad y calidad del queso Danbo. [s.1.]: MERCOSUR, 1996. (MERCOSUR/GMC/RES, 29/96)

- MONNET, V.; CHAPOT-CHARTIER, M. P.; GRIPON, J. C. Les peptidases des lactocoques. En: Lait, 1993, 73:97-108.

- POVEDA, J.M. Efecto de la utilización de distintos cultivos iniciadores en la proteólisis del queso manchego. Otros aspectos de la maduración. Ciudad Real: Universidad de Castilla-La Mancha, 2001. (Tesis de Doctorado)

- PRITCHARD, G. G.; COOLBEAR, T. The physiology and biochemistry of the proteolytic system in lactic acid bacteria. En: FEMS Microbiology Reviews. 1993, 12:179-206.

- SANCHEZ-PONTE, M. D. Maduración acelerada de queso con bacterias lácticas atenuadas térmicamente. En: Revista Cientifica, FCV - LUZ. 2003, 13(4):299-306.

- SORENSEN, J; BENFELDT, C. Comparison of ripening characteristics of Danbo cheeses from two dairies. En: International Dairy Journal. 2001, 11:355-362.

- SPADOTI, L.M.; FERREIRA DORNELLAS, J. R.; MASSAGUER ROIG, S. Proteolysis of prato type cheese produced using ultrafiltration. En: Sci. Agric. 2005, 62(3): 235-239.

- STATPOINT TECHNOLOGIES, INC. Statgraphics Plus [Software]. 7.0. Warrenton: Statpoint Technologies, INC., [s.d.].

- YVON, M.; CHABANET, C.; PÉLISSIER, J.P. Solubility of peptides in trichloroacetic acid (TCA) solutions. En: Int. J. Peptide Protein Res. 1989, 34:166-176. 